\title{
Lessons learned in developing community mental health care in North America
}

\author{
Robert E. Drake ${ }^{1}$, Eric Latimer ${ }^{2}$ \\ ${ }^{1}$ Dartmouth Psychiatric Research Center and Dartmouth Medical School, Rivermill Complex, 85 Mechanic St., Lebanon, NH 03766, USA \\ ${ }^{2}$ Douglas Mental Health University Institute and McGill University, Montreal, Canada
}

\begin{abstract}
This paper summarizes the findings for North America of the WPA Task Force on Steps, Obstacles and Mistakes to Avoid in the Implementation of Community Mental Health Care. Community mental health has evolved over five decades in the United States and Canada. The United States has led the world in innovation and spending, but provide variable quality of care; Canada has steadily developed a more uniform public health system for less cost. Lessons learned from North America include: team-based approaches and other evidence-based practices, when implemented with high fidelity, can improve outcomes in routine mental health care settings; recovery ideology and peer support enhance care, though they have not been studied rigorously; effective community-based care for people with serious mental disorders is expensive.
\end{abstract}

Key words: Community mental health care, United States, Canada, evidence-based practices, recovery, team-based care, psychiatric rehabilitation

(World Psychiatry 2012;11:47-51)

This paper is part of a series describing the development of community mental health care in regions around the world (see 1,2), produced by a Task Force appointed by the WPA as part of its Action Plan 2008-2011 $(3,4)$. The WPA Guidance on Steps, Obstacles and Mistakes to Avoid in the Implementation of Community Mental Health Care, developed by this Task Force, has been previously published in the journal (5). In this article, we describe these issues in relation to North America.

The paper reviews the evolution of community mental health care in the United States and Canada and highlights several principles based on the experiences of these two close neighbors. In spite of their geographical proximity and common language (the province of Québec excepted), the United States and Canada have distinct cultures and significantly different health care systems. These differences extend to the organization of community mental health care. Accordingly, we describe community mental health care separately for each country. The discussion of lessons learned brings together observations drawn from the experiences of both countries.

\section{THE UNITED STATES COMMUNITY MENTAL HEALTH SYSTEM}

The United States has numerous mental health systems, independent agencies, and single providers. A mixture of primary care providers and private practice therapists delivers most of the mental health care to people with non-severe mental disorders. For those with severe disorders, such as schizophrenia, bipolar disorder, and chronic depression, each of the 50 states oversees a public mental health pro- gram. Larger states often devolve responsibility to county or city authorities, so that there are actually multiple mental health care authorities and systems within many states. The only administrative commonality across states is funding by the federal Medicaid and Medicare programs for those who are impoverished, disabled, or aging. Medicaid is, however, administered differently in each state according to a variety of rules, regulations, and waivers. In addition to state public mental health programs, the federal government runs separate health care systems for active members of the military, for retired and disabled members of the military, and for Native Americans. For people with substance use disorders, the system is somewhat simpler, because the private sector is relatively small and the federal government supports most of the public care, with states contributing different amounts.

The organization of these many systems, programs, and providers is typically based on funding and profits rather than on public health needs, the preferences of users of the mental health services, or research. Few of the systems, programs, or individual practitioners collect data on quality or outcomes. Because so many providers, programs, and intermediaries (e.g., insurance agencies and managed care organizations) participate in the context of a largely private, for-profit system, health care costs are very large. The United States health care system expenditures were approximately 2.5 trillion dollars in 2009 (6). Of this total, $5-12 \%$ has been devoted to behavioral health care in recent years (7). The United States also spends much more than any other country on medical research. One advantage of the tremendous variation of programs and expenditures across regions has been the opportunity for innovation and research. 


\section{History}

The community mental health movement began in the United States in 1963, when President John Kennedy signed the Community Mental Health Act and community mental health centers arose in towns and cities throughout the country (8). Initially, these centers assumed too broad an agenda, including all mental health problems and prevention as well as treatment. By the 1970s, community mental health programs narrowed their goals to treatment of persons with long-term and disabling illnesses and facilitated deinstitutionalization of this population. Many long-term patients were actually transferred to group homes, nursing homes, and other institutions in the community, but the deinstitutionalization philosophy did result in significant downsizing of large state hospitals and of the total hospitalized population. The population in large public mental hospitals dropped from over 500,000 to less than 150,000 (8).

During the 1980s and 1990s, two movements strongly influenced community mental health care in the United States. The evidence-based practice movement arose from effectiveness research and evidence-based medicine, and, somewhat later, the recovery movement arose from the experiences of users of the mental health system.

\section{Models of care and evidence-based practices}

The initial plan for community care, developed by the National Institute of Mental Health and termed the Community Support Program, centrally featured professional case managers, who would coordinate and broker all of the services for people with severe and persistent mental disorders in the community (9). In the 1970s and 1980s, many challenges of caring for people in the community began to be apparent. Common concerns included integration and continuity of services for those with the most complex needs, appropriate housing, family burden, substance abuse and dependence, victimization, and violence (9). More recently, unemployment, criminalization, and early mortality of people with mental illnesses have emerged as major concerns. All of these problems were exacerbated by poverty, reductions in housing subsidies, and shunting of people with mental illnesses into inner-city areas plagued by unemployment, crime, and drugs.

Many models of care were developed to address the special problems of people with severe mental disorders living in the community (10). For integration and continuity of care, assertive community treatment, intensive case management, clinical case management, and other models appeared. To address the need for housing, foster care, Fairweather Lodge, residential continuum, and supportive and supported housing models emerged. Likewise, other concerns were addressed by a variety of family interventions, treatments for co-occurring disorders, and so on. Research has supported some of these models and not others. Research-based mod- els of care became identified as evidence-based practices. Various government reviews $(11,12)$ and systematic reviews (13-15) have identified specific interventions as evidencebased practices.

An additional concern has been the general failure to implement effective services in routine mental health treatment settings (16). In 1997, the Robert Wood Johnson Foundation, the Substance Abuse and Mental Services Administration, several State Departments of Mental Health, and additional private foundations initiated a national demonstration to implement six specific evidence-based practices that were deemed essential community mental health services: systematic medication management, assertive community treatment, supported employment, family psychoeducation, illness management and recovery, and integrated treatment for co-occurring disorders (17). Because of research showing that faithfulness to evidence-based practices was strongly related to outcomes, the project emphasized implementation and fidelity. Outcomes showed that, with training and supervision for one year, most programs were able to implement and sustain high-quality evidence-based practices $(18,19)$. Nevertheless, the degree of implementation of these practices varies widely from state to state (20).

\section{Recovery}

Approximately half of all people with severe and persistent mental illnesses in the United States have received no mental health services in the past year, often because they have rejected the available services (21). Many others who have received mental health services have expressed dissatisfaction with the services. Users of the mental health system (variously called patients, clients, users, consumers, or survivors) have lodged strong objections to the existing mental health system. They have also argued that professionals' goal of stabilization does not correspond to their aspirations for "recovery" (22), a concept defined by each individual, but which typically encompasses opportunities for education, work, friendship, independent living, and community participation (11). They also argued for meaningful roles in making decisions and in delivering mental health care, and for the elimination of coercion in the contexts of hospitalization, prescribing of medications, and outpatient treatment.

The recovery movement has influenced numerous changes in community mental health care. Many states embrace recovery at the level of philosophy and mission, even if they have varying levels of success implementing its tenets. Rehabilitative services are more widely available, and many mental health programs have decreased the use of coercive measures, such as seclusion and restraint. The impact of the recovery movement has been much greater in some states than others (20). 


\section{Recent developments}

In the 2000s, community mental health care in the United States was dominated by attempts to control costs. These included managed care, fee-for-service systems, and Medicaid audits, which resulted in the government demanding that millions of dollars be returned. The financial recession severely affected state budgets and led to numerous cycles of financial cuts. The $15 \%$ of citizens without insurance (higher for those with mental illnesses) had great difficulty accessing even minimal care (23). The net result has been a dramatic deterioration of community mental health care for people with the most severe disorders $(11,20,24)$.

Very recently, parity legislation and health care reform legislation offer hope that people with mental illnesses in the United States will more easily acquire insurance and that mental health disorders will be treated in the same manner as physical health disorders. How these two pieces of legislation are enacted over the next decade remains to be seen.

\section{THE CANADIAN COMMUNITY MENTAL HEALTH SYSTEM}

Analogously to the situation in the United States, each of Canada's ten provinces and three (Northern) territories has its own mental health care system: health care for the great majority of the population falls under provincial and territorial jurisdiction. Nonetheless, several factors, including various institutional features common across all provinces, common proximity to the United States, which has had a major influence on service development in Canada $(25,26)$, federally-managed equalization payments from richer to poorer provinces, and various mechanisms of exchange of information across provinces, have resulted in provincial mental health care systems bearing fairly close resemblance to each other. Partly due to equalization payments, perhaps partly also due to greater homogeneity in outlook concerning the resources needing to be allocated to the care of people with mental illness, per capita levels of funding for mental health are more similar to each other across Canadian provinces than they are across the United States. Health care spending per capita in Canada is about half what it is in real terms in the United States. A recent report estimated that in 2007/2008 total behavioral health spending in Canada was $7.2 \%$ of total health care spending, with per capita spending for inpatient mental health care, physician mental health services, and pharmaceuticals together varying from \$156 in Saskatchewan to \$240 in New Brunswick (27).

Common features of the Canadian mental health system include: a) a mix of institutionally-based services delivered by unionized professionals and less regulated, non-unionized voluntary sector providers; b) universal coverage of hospital and physician services, as well as those of voluntary sector providers - but no public coverage of psychologists practicing independently; c) public coverage of medications for seniors and social assistance recipients, with some prov- inces providing varying levels of coverage for other people not covered by supplementary employer-based private insurance; d) physicians, including hospital-based psychiatrists, who are paid directly by provincial governments, mostly on a fee-for-service basis; e) now with the notable exception of Alberta, regionalization of care delivery, resulting in further differentiation of community mental health services within individual provinces.

As in the United States, deinstitutionalization began in the late 1950s or early 1960s and was followed by the development of psychiatry departments within general hospitals. Voluntary sector providers quickly emerged to offer community-based care to the growing number of people with severe mental illness living in the community. Psychiatry departments and psychiatric hospitals gradually followed, adding community mental health services to their programming. This process has been slow, following the evidence base with a lag measured in decades, and even today a number of psychiatry departments have hardly embarked on it. Access to evidence-based practices remains, as in the United States, very limited.

As in the United States, there has been much discussion of recovery. Peer-support workers have become more commonly embedded into clinical services, and the notion that people with lived experience of mental illness should participate in administrative decisions and in research projects that have implications for them has gradually gained ground.

Some long-standing features of Canadian mental health care systems impede the development of high-quality community mental health care. Psychiatrists, who necessarily play a key role in community mental health care delivery, are paid directly by provincial governments independently of the quality of care they provide and have limited accountability. Union rules often seem designed to protect the privileges of members, especially those with more seniority, rather than serve the needs of clients. Funding for medications is open-ended while funding for psychosocial services is severely constrained.

In 2006, after extensive consultation, the Standing Senate Committee on Social Affairs, Science and Technology tabled an influential report that painted a grim picture of the state of mental health and addiction services in Canada (28). Services have not been well integrated and it is difficult, indeed often impossible, for people with mental illness and their caregivers to navigate successfully through them. Affordable, decent supportive or supported housing is often unavailable, as are integrated services for people with concurrent (mental illness and substance use) disorders and employment services. Much more often than should be the case, what care is accessed is of questionable quality. Stigma is a common, disabling experience.

Following a key recommendation of the report, in 2007 the federal government established the Mental Health Commission of Canada, whose mandate is "to help bring into being an integrated mental health system that places people living with mental illness at its centre". Whatever its ultimate 
impact on provincial and territorial mental health policies and services, the Commission has stimulated an unprecedented sharing of ideas and perspectives across a broad range of stakeholders throughout the country.

\section{LESSONS LEARNED IN NORTH AMERICAN COMMUNITY MENTAL HEALTH FROM 1960 TO 2010}

During five decades of developing community mental health programs in North America, several robust and durable concepts have emerged. These concepts contrast with many transient ideas that were never implemented broadly in real-world systems of care. The concepts correspond only loosely with research because research-based interventions sometimes fail to interest clients, providers, or payers. Some interventions take root and blossom over decades without much of a research base.

\section{Team-based care}

For people who have the most severe illnesses, the greatest disabilities, and the fewest family or community supports, integration of treatment, rehabilitation and support services needs to be achieved at the clinical level (29). Team-based care is the most straightforward way to insure access, continuity, and integration of services. Teams make it possible to offer clients an individualized, coherent, and long-term program of medical, psychiatric, housing, financial, vocational, family, and social services to help them in achieving their own goals. This insight emerged more than 30 years ago during early development of the assertive community treatment model and remains valid today.

\section{Recovery}

The recovery movement has spawned several important implications for the service delivery system: a) it calls for widespread participation of peer support workers within all types of services, and indeed, in the administration of and research on those services; b) it emphasizes choice and selfdetermination, so that the focus of services becomes helping clients achieve their own goals, as far as possible in their own way; c) it demands the replacement of unnecessarily coercive practices in favor of more clinically-skilled, creative interactions within the context of mutually respectful, collaborative partnerships; and d) it also calls for funding consumer-run programs of various types that may have a weaker evidence base but are favored by many people with mental illnesses.

\section{Psychiatric rehabilitation and evidence-based practices}

With its attention to the individual's goals, values, and preferences, the recovery movement has been consonant with parallel developments in the mental health field called psychiatric rehabilitation. One seminal paper described recovery as "the lived experience of rehabilitation" (22). Within the rehabilitation movement, values (people first) and goals (successful adjustment in one's psychosocial areas of preference) have been consistent, methods and outcomes measurement have evolved, and evidence-based practices have emerged (10). Earlier stepwise approaches to rehabilitation based on lengthy psychotherapy and training programs have gradually been replaced by more modern approaches that involve helping clients to reach their goals rapidly by providing highly individualized supports. Exemplars of the current approaches are supported housing, supported employment, supported education, and strengths case management.

\section{Peer support}

Social and instrumental support among peers with similar conditions has a long and robust history in North America. Alcoholics Anonymous, for example, has grown steadily since its development in the 1940s, and millions of people with alcoholism now attend Alcoholics Anonymous meetings in cities, suburbs, and towns throughout the region. Peer support programs for people with severe and persistent mental disorders have proliferated for several decades (30). Like Alcoholics Anonymous, they have been supported by the strong endorsement of people with these disorders themselves rather than by randomized controlled trials. Some $10 \%$ to $20 \%$ of people with severe mental disorders find these services helpful as a substitute or an adjunct to community mental health services. The forms of peer services continue to evolve, but the concept has been enduring.

\section{Economic consequences of neglect}

In any mental health service system, a minority of individuals with mental illness consume a disproportionate share of expensive resources such as inpatient care, emergency room visits, incarcerations, and so on. Providing comprehensive, team-based care to these individuals is expensive, but it mitigates personal suffering, is no more costly, and avoids shifting the costs to families, communities, and the criminal justice system (31-33).

\section{Implementation}

As evidence-based practices have been defined with increasing precision and model fidelity, the inadequacy of brief training of front-line staff and team leaders has become clear. High fidelity implementation requires ongoing training and supervision for six months to a year, and maintaining high quality services also requires ongoing supervision (34-36). 


\section{CONCLUSIONS}

The story of the development of community-based mental health services in the United States has been one of both hope and disappointment. It has been one of hope in that many of the most important innovations in the field have arisen there, from the most long-standing, extensive and influential program of mental health services research in the world, as well as from a plethora of consumer initiatives; and also in that a few states have been trailblazers in showing how these advances can be turned into effective programs that actually help people with mental illnesses to recover. It has also been one of disappointment in that the political will and the funding levels needed to ensure development of these programs across the country have more often than not been lacking. Health care reform initiated by President Obama may change these trends.

Canada has imported many ideas from its larger neighbor to the south. While funding levels are more uniform than in the United States, and may be about adequate for good quality care to be delivered throughout, various institutional arrangements, combined with lack of political will, have impeded the integration of state-of-the-art practices into routine care. Recent recognition of these failings by the federal government and the establishment of the Mental Health Commission of Canada may now lead to a period of accelerated progress.

\section{References}

1. Hanlon C, Wondimagegn D, Alem A. Lessons learned in developing community mental health care in Africa. World Psychiatry 2010;9: 185-9.

2. Semrau M, Barley E, Law A et al. Lessons learned in developing community mental health care in Europe. World Psychiatry 2011;10:21725.

3. Maj M. The WPA Action Plan 2008-2011. World Psychiatry 2008;7: 129-30.

4. Maj M. Report on the implementation of the WPA Action Plan 2008-2011. World Psychiatry 2011;10:161-4.

5. Thornicroft G, Alem A, Dos Santos RA et al. WPA guidance on steps, obstacles and mistakes to avoid in the implementation of community mental health care. World Psychiatry 2010;9:67-77.

6. Centers for Medicare and Medicaid Services. National health care expenditures data. Baltimore: Centers for Medicare and Medicaid Services, 2010.

7. Frank R, Goldman H, McGuire T. Trends in mental health cost growth: an expanded role for management? Health Affairs 2009;28: 649-59.

8. Dixon L, Goldman H. Forty years of progress in community mental health: the role of evidence-based practices. Aust N Z J Psychiatry 2003:37:668-73.

9. Turner J, TenHoor W. The NIMH community support program: pilot approach to a needed social reform. Schizophr Bull 1978;4:319-48.

10. Corrigan P, Mueser K, Bond G et al. The principles and practice of psychiatric rehabilitation. New York: Guilford, 2008.

11. New Freedom Commission on Mental Health. Achieving the promise: transforming mental health care in America. Rockville: U.S. Department of Health and Human Services, 2003.

12. U.S. Department of Health and Human Services. Mental health: a report of the Surgeon General. Rockville: U.S. Department of
Health and Human Services, 1999

13. Chambless D, Ollendick T. Empirically supported psychological interventions: controversies and evidence. Annu Rev Psychol 2001; 52:685-716.

14. Cook J. Blazing new trails: using evidence-based practice and stakeholder consensus to enhance psychosocial rehabilitation services in Texas. Psychiatr Rehab J 2004;27:305-6.

15. Kreyenbuhl J, Buchanan R, Dickerson F et al. The Schizophrenia Patient Outcomes Research Team (PORT): updated treatment recommendations 2009. Schizophr Bull 2010;36:94-103.

16. Torrey W, Drake R, Dixon L et al. Implementing evidence-based practices for persons with severe mental illnesses. Psychiatr Serv 2001;52:45-50.

17. Drake R, Goldman H, Leff $\mathrm{H}$ et al. Implementing evidence-based practices in routine mental health service settings. Psychiatr Serv 2001;52:179-82

18. McHugo G, Drake R, Whitley R et al. Fidelity outcomes in the National Implementing Evidence-Based Practices Project. Psychiatr Serv 2007;58:1279-84.

19. Swain K, Whitley R, McHugo G et al. The sustainability of evidence-based practices in routine mental health agencies. Commun Ment Health J 2010;46:119-29.

20. National Alliance on Mental Illness. Grading the States: a report on America's health care system for serious mental illness. Arlington: National Alliance on Mental Illness, 2006.

21. Mojtabai R, Fochtmann L, Chang S et al. Unmet need for mental health care in schizophrenia: an overview of literature and new data from a first-admission study. Schizophr Bull 2009;35:679-95.

22. Deegan P. Recovery: the lived experience of rehabilitation. Psychosoc Rehab J 1988;11:11-9.

23. Cunningham P, McKenzie K, Taylor E. The struggle to provide community-based care to low-income people with serious mental illness. Health Aff 2006;25:694-705.

24. Glied R, Frank R. Better but not best: recent trends in the well-being of the mentally ill. Health Affairs 2009;28:637-48.

25. Goering P, Wasylenki D, Durbin J. Canada's mental health system. Int J Law Psychiatry 2000;23:345-59.

26. Rochefort D, Goering P. "More a link than division": how Canada has learned from U.S. mental health policy. Health Affairs 1998;17: 110-27.

27. Jacobs P, Dewa C, Lesage A et al. The cost of mental health and substance abuse in Canada. Alberta: Institute of Health Economics, 2010.

28. Standing Senate Committee on Social Affairs. Out of the shadows at last: transforming mental health, mental illness and addiction services in Canada. Ottawa: Government of Canada, 2006.

29. Lehman A, Kreyenbuhl J, Buchanan R et al. The Schizophrenia Patient Outcomes Research Team (PORT): updated treatment recommendations 2003. Schizophr Bull 2004;30:193-217.

30. Solomon P. Peer support/peer provided services underlying processes, benefits, and critical ingredients. Psychiatr Rehab J 2004;27: 392-401.

31. Culhane D. The costs of homelessness: a perspective from the United States. Eur J Homelessness 2008;2:97-114.

32. Larimer M, Malone D, Garner M et al. Health care and public service use and costs before and after provision of housing for chronically homeless persons with severe alcohol problems. JAMA 2009; 301:1349-57.

33. Latimer E. Economic impacts of assertive community treatment: a review of the literature. Can J Psychiatry 1999;44:443-54.

34. Drake R, Bond G, Essock S. Implementing evidence-based practices for people with schizophrenia. Schizophr Bull 2009;35:704-13.

35. Fixsen D, Naoom S, Blase K et al. Implementation research: a synthesis of the literature. Tampa: University of South Florida, 2005.

36. Rapp C, Etzel-Wise D, Marty D et al. Evidence-based practice implementation strategies: results of a qualitative study. Commun Ment Health J 2008;44:213-24. 